\title{
LÍNGUA, ENSINO E DISCURSO: DO MESMO AO DIFERENTE
}

\author{
LANGUAGE, TEACHING AND DISCOURSE: FROM THE SAME TO THE DIFFERENT
}

\author{
Marilei Resmini Grantham ${ }^{1}$ \\ ${ }^{1}$ Universidade Federal do Rio Grande (FURG), Rio Grande, RS, Brasil \\ grantham@vetorial.net
}

Recebido em 7 out. 2019

Aceito em 9 dez. 2019

Resumo: O objetivo deste texto é produzir uma reflexão sobre ensino de língua a partir de uma concepção discursiva e, mais precisamente, sob a perspectiva da Análise do Discurso. Falar em língua e ensino, a partir dessa concepção, nos leva a pensar sobre o professor, considerando-o como sujeito: não um sujeito empírico, mas um sujeito que é uma posição, um lugar, que se constitui no discurso e que é submetido tanto à língua quanto à história para produzir sentidos. Para compreender como se produz o imaginário sobre o professor, traçamos um breve panorama histórico, pensando no seu papel em diferentes épocas. Para discutir todas essas questões, tomamos para análise três enunciados que estabelecem relação com outros, semelhantes, de domínio público e que pertencem ao gênero dos provérbios. Tal exame nos remete aos conceitos de paráfrase e polissemia, sendo a primeira considerada como retorno a um mesmo dizer sedimentado e a segunda como tensão que aponta para o rompimento. Mostramos que tais conceitos estão relacionados à tipologia de discursos de Orlandi (1987), que os divide em autoritário, polêmico e lúdico. A partir desses três tipos de discurso, refletimos sobre o que a autora denomina de Discurso Pedagógico (DP), procurando examinar seu funcionamento. Procuramos, finalmente, colocar em evidência que assumir uma perspectiva discursiva de língua e de ensino significa, para o professor, descolar-se de um discurso autoritário, que reforça o mesmo, e procurar instaurar um discurso polêmico ou lúdico, que abre espaço para o diferente.

Palavras-chave: Língua. Discurso. Ensino.

Abstract: The aim of this text is to produce a reflection on language teaching from a discursive conception and, more precisely, from the perspective of Discourse Analysis of French affiliation. Speaking in language and teaching, from this conception, leads us to think about the teacher, considering him as a subject: not a formal subject-in-itself, but a subject that is a position, a place, constituted in discourse and subjected to both language and history to produce meanings. To understand how the imagination about the teacher is produced, we draw a brief historical overview, thinking about his role in different times. In order to discuss all these questions, we take into consideration three statements that relate to similar, public domain statements that belong to the genre of proverbs. This examination brings us to the concepts of paraphrase and polysemy, being the first considered as a return to the same sedimented saying and the second as tension that points to the rupture. We show that these concepts are related to Orlandi's typology of discourse (2009), which divides them into authoritarian, controversial and playful. From these three types of discourse, we reflect on what the author calls Pedagogical Discourse (PD), seeking to examine its characteristics. Finally, we seek to highlight that assuming a discursive perspective of language and teaching means, for the teacher, to detach from an authoritarian discourse, which reinforces it, and to seek to establish a controversial or playful discourse, which opens space for the different.

Keywords: Language. Speech. Teaching. 
O título que encabeça este texto me impõe, de antemão e inevitavelmente, a tarefa de refletir sobre três conceitos: língua, ensino e discurso. Dos três, o terceiro discurso - aponta o lugar de onde falo - como analista do discurso - e a partir do qual considero os outros dois, língua e ensino.

Dou início então à minha reflexão pensando sobre um personagem que tem relação direta com esses conceitos: o professor de língua. Na concepção que assumo, a da Análise do Discurso, o professor não pode ser visto como um indivíduo particular - com nome, sobrenome e endereço - mas como um sujeito que, sob a perspectiva da Análise do Discurso, não é um sujeito empírico, coincidente consigo mesmo. Cito então Orlandi, quando a autora discorre sobre a noção de sujeito:

\begin{abstract}
Ele é materialmente dividido desde sua constituição: ele é sujeito de e sujeito à. Ele é sujeito à língua e à história, pois para se constituir, para (se) produzir sentidos ele é afetado por elas. Ele é assim determinado, pois se não sofrer os efeitos do simbólico, ou seja, se ele não se submeter à língua e à história ele não se constitui, ele não fala, não produz sentidos. (ORLANDI, 1999, p. 49).
\end{abstract}

Neste modo de pensar, nem sujeito nem sentidos - e acrescento: nem o sujeito-professor, nem os sentidos produzidos no discurso do/sobre o professor são constituídos a priori, mas são constituídos no discurso. Essa constatação traz em sua base Pêcheux, quando o autor afirma que "o sentido de uma palavra, uma expressão, de uma proposição, etc., não existe 'em si mesmo". (PÊCHEUX, 1988, p. 160). Para o autor, as palavras adquirem seu sentido segundo as posições sustentadas por aqueles que as empregam, isto é, com referência às formações ideológicas $(\mathrm{FI})^{1}$ de quem usa essas palavras e expressões.

Tais considerações permitem que se considere o sujeito - e, neste caso, 0 sujeito-professor - como uma posição, como um lugar que ocupa para ser sujeito do que diz. O modo como o sujeito - e esse sujeito-professor - ocupa esse lugar não Ihe é acessível, da mesma forma que a língua não é transparente nem o mundo diretamente apreensível. A ideologia é a condição para a constituição do sujeito e

\footnotetext{
${ }^{1}$ A noção de formação ideológica serve para caracterizar um elemento suscetível de intervir como uma força de confrontação com outras forças na conjuntura ideológica característica de uma formação social em um dado momento. Cada formação ideológica constitui "um conjunto complexo de atitudes e de representações que não são nem individuais nem universais, mas se relacionam mais ou menos diretamente a posições de classe em conflito umas com as outras". (PÊCHEUX; FUCHS, 1975, p. 166).
} 
dos sentidos. Em outras palavras: o indivíduo é interpelado pela ideologia em sujeito - e em sujeito-professor - para que se produza o seu dizer.

Estamos diante de um conceito de um sujeito da linguagem que não é o sujeito-em-si, mas tal como existe socialmente. Sendo assim, a evidência do(s) sentido(s) é um efeito ideológico, que não deixa perceber a historicidade de sua construção e faz perceber como transparente aquilo que, de fato, consiste em uma remissão a um conjunto de formações discursivas (FD) ${ }^{2}$.

Pergunto então: o que fala antes, em outro lugar, em relação a este lugar social de professor? Que saber discursivo torna possível o dizer do/sobre o professor? $\mathrm{Na}$ tentativa de obter uma resposta, tento reconstruir, muito brevemente, o panorama histórico que sustenta esse imaginário sobre educação e sobre o ser professor.

Pensando sobre a identidade dos mestres na ldade Média (entre o século V e o século XV), vou a Geraldi (1993, p. 86), autor que, abordando esse tema, delara que, nesta época, os mestres e suas escolas são a sobrevivência do que se poderia chamar "a escola de sábios". Escolas onde o professor, pago ou não por seus alunos, pela comunidade ou sustentado pela abadia, se caracterizava por ser um produtor de conhecimentos, um produtor do saber. E era como tal que falava sobre esse saber a seu aluno. Este, por sua vez, não era visto como alguém a ser instruído (ainda que se the desse instrução), mas como alguém a ser considerado e conquistado para os pontos de vista defendidos pelo 'sábio'. Sócrates, Platão, Aristóteles ou o gramático Varrão foram produtores de saber, e seus alunos discíplulos - eram interlocutores, aprendizes que, com o mestre, produziam conhecimento. O que marca este tempo, que vai até o início da Modernidade, é o fato de que, entre aquele que ensinava e aquele que produzia conhecimento, não havia uma separação radical.

Já nos primórdios do Mercantilismo, na Idade Moderna, entre os séculos XV e XVIII, acontece, conforme Geraldi, uma divisão radical, uma divisão social do trabalho, responsável pelo surgimento de uma nova identidade: "o mestre já não se constitui pelo saber que produz, mas por ser um saber produzido que ele transmite".

\footnotetext{
${ }^{2}$ Segundo Pêcheux (1975), a FD determina "o que pode e deve ser dito", o que significa que o sentido de uma sequência só é materialmente concebível na medida em que se concebe esta sequência como pertencente necessariamente a esta ou àquela formação discursiva." (PÊCHEUX; FUCHS, 1975, p. 169).
} 
(GERALDI, 1993, p. 87). É neste contexto que emerge na história o professor. De produtores a transmissores: uma nova identidade. $\mathrm{E}$, do outro lado, também uma nova identidade: de discípulos a alunos.

Creio que este cenário todo contribui para a construção do imaginário sobre o discurso escolar até os dias de hoje, um discurso em que os protagonistas professor e aluno - ocupam lugares determinados na estrutura de uma formação social; a relação entre esses lugares é representada por uma série de formações imaginárias, que designam o lugar que destinador e destinatário - professor e aluno - atribuem a si mesmo e ao outro, ou seja, a imagem que eles fazem do seu próprio lugar e do lugar do outro.

Orlandi (1987) trata desse tema em termos de Discurso Pedagógico (DP) e afirma que a escola atua pela legitimidade desse discurso. A autora define o discurso pedagógico como "um discurso circular, isto é, um dizer institucionalizado, sobre as coisas, que se garante, garantindo a instituição em que se origina e para a qual tende: a escola. $O$ fato de estar vinculado à escola, a uma instituição, portanto, faz do DP aquilo que ele é, e o mostra (revela) em sua função". (ORLANDI, 1987, p. 28). A escola, nestes moldes, institui-se por regulamentos, por máximas, por modelos. Ela atua pelo prestígio de legitimidade e pelo seu discurso, o DP.

Em sua definição, o DP seria um discurso neutro, que transmite informação (teórica ou científica). Um discurso que não teria sujeito, na medida em que qualquer um, dentro das regras do jogo, poderia ser seu sujeito. No entanto, na prática, segundo Orlandi, não há neutralidade no DP, pois, na verdade, é um discurso que evita a produção e estimula a transmissão, a reprodução; um discurso que evita mostrar a tensão entre o mesmo e o diferente.

Tal tensão está presente na distinção criada por Orlandi entre paráfrase e polissemia. O processo parafrástico é entendido pela autora como matriz de sentido e origina-se da reiteração de processos cristalizados pelas instituições, enquanto o processo polissêmico é entendido como fonte de sentido e relaciona-se à multiplicidade, que é a própria condição da linguagem. Afirma Orlandi: "A polissemia se define como multiplicidade de sentidos e a paráfrase como sendo formulações diferentes para o mesmo sentido". (ORLANDI, 1987, p. 84). Para a autora, estes são dois processos fundamentais da linguagem, sendo a paráfrase considerada como o processo que "mantém o homem num retorno constante a um mesmo espaço 
dizível" e a polissemia "como o processo que instaura o diferente, causando um deslocamento deste dizível." (ORLANDI, 1987, p. 137). Constitui-se, assim, a tensão entre paráfrase e polissemia: de um lado, o retorno a um mesmo dizer sedimentado; de outro, o que aponta para o rompimento. Um conflito entre o garantido e o que quer se garantir.

A consideração de tais pressupostos não permite considerar o discurso como simples transmissão de informação, mas como efeitos de sentido, já que o conflito é entre o texto e o contexto histórico-social. Destaca Orlandi: "Dessa maneira, o social aparece em relação à linguagem, na sua força contraditória: porque o social é constitutivo da linguagem, esta se sedimenta (ilusão do sujeito) e porque é fato social, ela muda (polissemia)" (ORLANDI, 1987, p. 28).

Com base nessa distinção entre paráfrase e polissemia, Orlandi propõe um funcionamento para os tipos de discurso: autoritário, polêmico e lúdico. O discurso autoritário é aquele que tende para a paráfrase, ou seja, é o que busca conter a polissemia, procurando impor um só sentido, tendo a reversibilidade (ou troca de papéis entre os protagonistas do discurso) praticamente nula. De forma distinta, o discurso polêmico é definido como aquele em que a reversibilidade se dá sob certas condições e no qual há um equilíbrio tenso entre paráfrase e polissemia, ou seja, onde a polissemia é controlada e há a possibilidade de mais de um sentido. Finalmente, na direção oposta ao discurso autoritário, o discurso lúdico é caracterizado como aquele em que a reversibilidade é total e que tende para a total polissemia.

A partir dessas premissas, Orlandi vai dizer que o Discurso Pedagógico inclinase para o autoritário, para o dizer institucionalizado e uníssono, que cristaliza as posições sociais de professor como aquele que detém o conhecimento e o poder, e a do aluno como aquele que precisa somente aprender (apreender) o conhecimento. No DP, "o professor é uma autoridade na sala de aula e não só mantém como se serve dessa garantia dada pelo seu lugar na hierarquia" (ORLANDI, 1987, p. 154).

Orlandi, no entanto, oferece uma forma de estabelecer uma posição crítica diante da caracterização do Discurso Pedagógico: transformá-lo de discurso autoritário em discurso polêmico. Isso significa uma prática que evite a imposição de um único sentido, que admita a reversibilidade (a troca de papeis entre os 
interlocutores do discurso), que aceite a possibilidade de sentidos múltiplos e que trabalhe a tensão entre o mesmo e o diferente, entre paráfrase e polissemia.

Assumir um novo papel no discurso pedagógico, portanto, significa, para o professor, abandonar o papel de mero transmissor, e, para o aluno, transformar-se em produtor de sentidos. Significa, para ambos, compreender que o ensino de uma língua não pode deixar de considerar as diferentes instâncias sociais e que a língua não pode ser estudada ou ensinada como um produto acabado, pronto, fechado em si mesmo, mas, pelo contrário, como um processo sempre inacabado, sempre em construção.

\section{ANALISANDO JÁ-DITOS E OUTROS DIZERES}

A fim de ilustrar as posições demonstradas até aqui, tomo, como corpus de análise, três enunciados que circulam na internet, sem autoria determinada, e que revelam relação com outros dizeres, já enunciados anteriormente, também de domínio público e também sem autoria. Esses enunciados já existentes têm como característica principal possuírem um sentido de sentença moral e são denominados de provérbios.

Apresento então, na primeira coluna, os enunciados que serão objeto de análise e, na coluna ao lado, o provérbio a que remetem:

Devagar nunca se chega.

Quem tudo quer, tudo tem.

Quem espera, sempre cansa.
Devagar se vai ao longe.

Quem tudo quer, tudo perde.

Quem espera, sempre alcança.

O reconhecimento dessa relação leva-me, automaticamente, ao tema da repetição. Cito então Courtine e Marandin, que afirmam: "Os discursos repetem-se sincronicamente, no fio de seu desenvolvimento, e diacronicamente, no fio do tempo", pois os mesmos temas, as mesmas formulações reaparecem" (COURTINE; MARANDIN, 1981, p. 27). É esse efeito de retorno que visualizo nos três enunciados apresentados, os quais fazem 'reaparecer' provérbios anteriormente produzidos.

Ocupando-se do discurso proverbial, Pereira o vê como um discurso de ação controladora, um tipo de censor moral ou guia de consciência que fornece ou impõe 
ao sujeito modelos de conduta, os quais fazem parte do sistema de valores que correspondem à ideologia dominante. Afirma a autora: "Tudo gira em torno da moderação e do autocontrole, contribuindo para o desenvolvimento do conformismo e para o estabelecimento de uma homogeneização da conduta social”. (PEREIRA, 1994, p. 38). Nos provérbios, assim, os enunciados ganham o estatuto de moral, a qual, por sua vez, tem relação com bons costumes e com os deveres do homem.

Tais constatações reportam-me a Lagazzi, quando esta afirma que o objetivo de todas as sociedades coercitivas "foi sempre o de chegar à melhor forma de assujeitar o sujeito a um poder que lhe fosse exterior" (LAGAZZI, 1988, p. 29). Situar as grandes verdades acima de todos os sistemas, colocando-os como senso comum, possibilita que não haja choque com o poder vigente.

Como é possível perceber, o conceito de senso comum relaciona-se diretamente ao de provérbio, pois ambos têm um caráter coercitivo, funcionando como um domínio de saber com o qual o sujeito se identifica (ou não). Desta forma, o senso comum - assim como o provérbio - barra a ideia do diferente, do múltiplo, rege a vida cotidiana e funciona como horizonte regulador, já que não são todas as crenças admitidas numa época e num meio dados, mas sim as formas históricas que ratificam o mesmo. Em suma, o senso comum refere-se àquilo que pode ser objeto do dizer e mantém à distância aquilo que não pode ser dito.

A partir dessas considerações, observo, de imediato, que os enunciados em análise (Devagar nunca se chega / Quem tudo quer, tudo tem / Quem espera, sempre cansa) não são o discurso do senso comum. E pergunto: Que análise linguística imanente pode dar conta dos sentidos que podem ser por eles produzidos?

Constato então que é impossível analisar essas sequências linguísticas como fechadas sobre elas mesmas, mas apenas referindo-as ao conjunto de discursos possíveis a partir de um estado definido de condições de produção. Ou seja: é preciso percebê-las pensando na linguagem como lugar de contrastes, confrontos, diferenças. Assim, procuro reestabelecer o senso comum nesses enunciados, 
buscando os outros enunciados, já-ditos, com os quais as sequências em análise mantêm uma relação de ressonância ${ }^{3}$.

Vou então chamar de (A) o conjunto de enunciados já-ditos e de domínio público, e, neste caso específico, os seguintes provérbios: Devagar se vai ao longe / Quem tudo quer, nada tem / Quem espera, sempre alcança. Tais enunciados funcionam, ilusoriamente, como 'enunciados-origem'. E vou denominar de (B) o conjunto dos 'novos' enunciados: Devagar nunca se chega / Quem tudo quer, tudo tem / Quem espera, sempre cansa.

Desta forma, percebo que, ao produzir os enunciados (B), o sujeito é afetado por dois tipos de esquecimento: um que lhe dá a ilusão de ser a fonte do sentido (esquecimento $\mathrm{n}^{0}$ 1) e outro que lhe dá a ilusão de ser dono de seu próprio processo de enunciação (esquecimento $\mathrm{n}^{\circ}$ 2). No discurso desse sujeito distinguem-se, então, uma base linguística (referente ao esquecimento $\mathrm{n}^{0}$ 1) e um processo discursivo (referente ao esquecimento $\mathrm{n}^{\circ}$ 2). Através da base linguística e do processo discursivo é que se chega à formação discursiva do sujeito de (B) - distinta da formação discursiva do sujeito enunciador dos enunciados de $(A)$ - a qual, segundo Pêcheux, "dissimula, pela transparência do sentido que nela se constitui, sua dependência com respeito ao todo complexo com dominante das formações discursivas" (PÊCHEUX, 1988, p. 162).

Pêcheux afirma então: "Propomos chamar interdiscurso a esse 'todo complexo com dominante' das formações discursivas, esclarecendo que também ele é submetido à lei de desigualdade - contradição - subordinação que, como dissemos, caracteriza o complexo das formações ideológicas" (PÊCHEUX, 1988, p. 162). interdiscurso constitui o exterior específico de uma FD e é o lugar no qual se constituem, pelo sujeito-falante, produzindo uma sequência discursiva dominada por uma FD determinada, os objetos de que este sujeito enunciador se apropria para usar como objetos de seu discurso. É através das articulações entre esses objetos que o sujeito enunciador dá coerência a seu propósito na sequência discursiva que enuncia, isto é, no intradiscurso.

\footnotetext{
${ }^{3}$ É de Serrani a noção de paráfrase como ressonância de significação, entendida essa ressonância como "um efeito de vibração semântica mútua". (SERRANI, 1993, p. 47).
} 
É, pois, nesta relação entre o interdiscurso de uma FD e o intradiscurso de uma sequência discursiva que se situam os processos pelos quais o sujeito falante é interpelado em sujeito do seu discurso. Nessas condições, a formação discursiva dissimula a objetividade material contraditória do interdiscurso, objetividade que reside no fato de que 'algo fala' sempre antes, em outro lugar e independentemente, ou seja, no fato de que há sempre um pré-construído. Este pré-construído, como elemento constitutivo do interdiscurso, designa então uma construção anterior, exterior e independente - os provérbios - por oposição ao que é construído na enunciação - os novos enunciados (B). Ele marca, assim, uma relação entre o interdiscurso, como lugar de construção do pré-construído, e o intradiscurso, como lugar da enunciação pelo sujeito.

Desta forma, é através do pré-construído que a FD com a qual se identifica o enunciador das sequências (B) relaciona-se com seu exterior. Lemos em Pêcheux que "uma FD não é um espaço estrutural fechado, pois é constitutivamente invadida por elementos que vêm de outro lugar". (PÊCHEUX, 1983, p. 314), ou seja, por elementos que vêm de outras FD e se repetem nela, fornecendo-Ihe suas evidências discursivas fundamentais sob a forma de pré-construídos.

Tudo isso constitui, neste discurso (B), o efeito da memória ${ }^{4}$, tomada como aquilo que fala antes, em outro lugar. Esta categoria foi trazida definitivamente para o âmbito da AD por Courtine (1981), que a trata não dentro de uma concepção individual ou de um inconsciente coletivo, mas, conforme ressalta Indursky, como "memória social inscrita no seio das práticas discursivas". (INDURSKY, 1992, p. 36). A memória, assim, é o saber discursivo que torna possível o novo dizer e que retorna sob a forma do pré-construído, do já-dito que está na base do dizível, sustentando a tomada da palavra.

As noções de pré-construído e de memória discursiva nos possibilitam perceber, assim, nos enunciados $(A)$ e (B), um jogo entre diferentes formações

\footnotetext{
${ }^{4}$ Courtine introduz a noção de memória discursiva e, com isso, articula a AD com a história. Ao adotar tal postura, conjuga os fundamentos de Foucault e Pêcheux, que postulam uma materialidade social e ideológica para o campo enunciativo. Para Courtine, é possível, a partir do enunciado [E], referir-se à memória discursiva, "a qual decorre da existência histórica do enunciado no seio das práticas discursivas, reguladas por aparelhos ideológicos" (COURTINE, 1981, p. 53). Desse modo, é a repetição ou o apagamento dos elementos do saber de uma FD, isto é, dos enunciados, que aponta para a memória discursiva.
} 
discursivas, o que acaba produzindo um contraste entre um estado de mundo cristalizado $(A)$ e outro estado de mundo, possível $(B)$.

Esse sentido cristalizado em (EO) corresponderia a uma espécie de sentido literal, isto é, um sentido-primeiro, um sentido-único. Sabemos, no entanto, a partir dos pressupostos da Análise do Discurso, que não existe sentido literal, uma vez que os sentidos são uma construção dos sujeitos, inseridos na prática discursiva. Em outras palavras, isso significa que a literalidade é somente um efeito, pois, na verdade, sentidos e sujeitos são constituídos em função das condições sociais, históricas, culturais. Os sentidos são produzidos a partir da ideologia, do imaginário. Desta forma, o sentido que se cristaliza, que se sedimenta, é aquele que, em uma dada sociedade e sob determinadas condições de produção, acaba conquistando o status de aceito, de único, de unanimidade.

Assim, quando surgem os novos enunciados (E1), estabelecendo uma ressonância com (EO), produz-se uma tensão com o já-dito, com o conhecido. E essa tensão produz um efeito de ironia nesse novo discurso.

Orlandi (1983) interessa-se pela ironia, examinando-a em sua relação com o processo de significação na linguagem. Para a autora, a reflexão sobre a ironia leva à compreensão de que, no estudo da significação, importa tanto o que é construção como o que é processo de autodestruição do sentido. Para ela, a ironia "é um desses lugares em que o processo de autodestruição do sentido mostra seu funcionamento". (ORLANDI, 1983, p. 67).

Vendo o funcionamento discursivo como a atividade de um discurso determinado, para um ouvinte determinado, e com finalidades específicas, Orlandi (1986) vai dizer que a ironia não está no locutor, não está no ouvinte, não está no texto, mas na relação que se estabelece entre os três. Para Orlandi, na ironia "jogase com a relação entre o estado de mundo tal como ele se apresenta já cristalizado - os discursos instituídos, o senso comum - e outros estados de mundo". (ORLANDI,1986, p. 84). Esse é o funcionamento básico da ironia.

Dessa forma, contrariando a opinião comum sobre a ironia, Orlandi diz que ela não se constitui em um simples jogo de oposição, de dizer o contrário do que se pensa; a diferença vai mais além e significa multiplamente. Considerando a ironia como um tipo de discurso, Orlandi nega que ela seja um desvio e diz que ela é o próprio lugar do estabelecimento de um processo de significação que ela chama de 
irônico. Esse lugar mostra a relação entre o mesmo e o diferente, o fixado e o possível.

Sob este ponto de vista, pode-se considerar a ironia como um gesto social de interpretação, pois a atribuição de sentidos às diferenças é uma questão de condições de produção: a diferença só faz sentido para quem conhece o mesmo, o conhecido. A ironia é, portanto, uma questão de interpretação: tanto por parte de quem a produz, quanto por parte de quem the atribui sentidos, pelo processo discursivo da leitura.

É o que verificamos no corpus em análise: usa-se uma enunciação original (EO) e, através dela, faz-se surgir uma nova enunciação (E1). Há, entre (EO) e (E1), então, algo comum e algo que as diferencia.

Esquematizando, temos:

(EO)

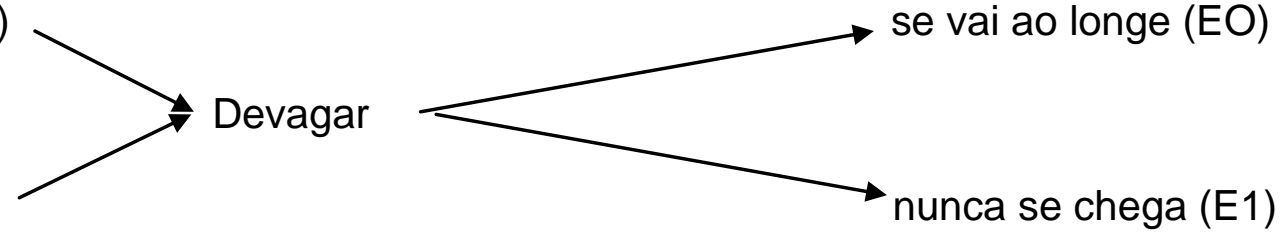

(A)

(EO)

(E1)

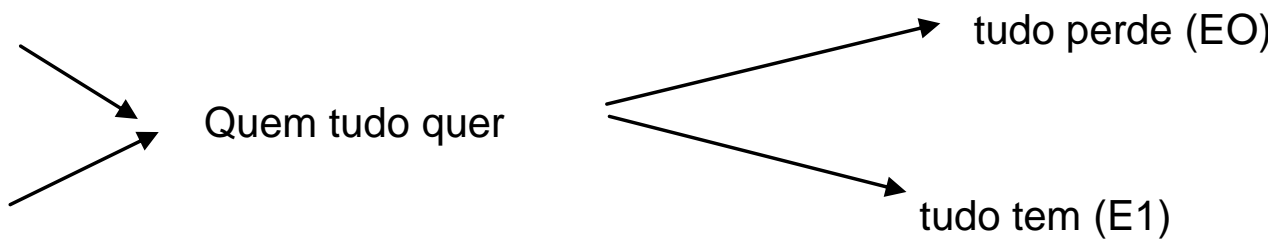

(A)

(B)

(EO)

(E1)

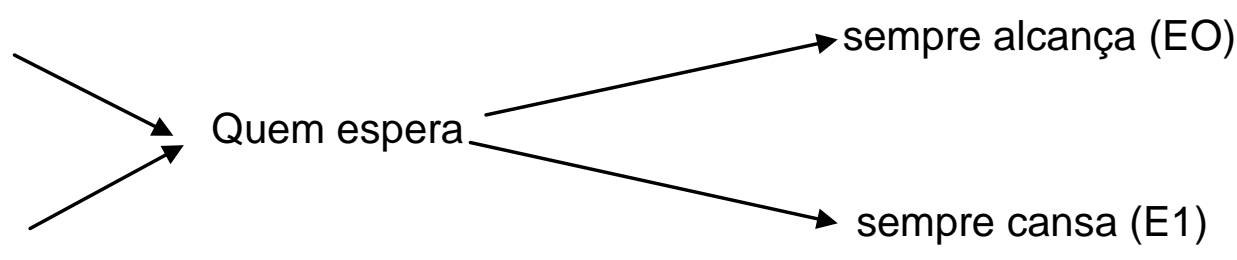


Conforme já afirmamos anteriormente, em (EO) os enunciados são provérbios. Já em (E1) estamos considerando os enunciados como novos provérbios que procuram desestabilizar a autoridade dos provérbios reconhecidos, construídos no intertexto $^{5}$. Em (E1), assim, temos um antimodelo, uma tentativa de romper com verdades estabelecidas no intertexto.

Tais considerações nos conduzem às ideias apresentadas por Grésillon e Maingueneau (1984), quando, ao fazerem um estudo dos provérbios, chamam de deslocamento o procedimento discursivo de produzir um enunciado que possui as marcas linguísticas da enunciação proverbial, mas que não aparece no estoque de provérbios reconhecidos. Os autores distinguem o deslocamento lúdico, que consiste em um puro jogo de palavras, e não entra a serviço de uma luta ideológica, do deslocamento militante, o qual visa a dar autoridade a um enunciado ou a desestabilizar aquela do provérbio, por interesses de diversas ordens. Quando se trata de confirmar autoridade proverbial, segundo Gréssillon e Maingueneau, tem-se a captação, e quando se trata de contestá-la, tem-se a subversão. Pela subversão, busca-se fazer aparecer uma contradição entre o sentido veiculado pela enunciação da estrutura original (EO) e aquela da enunciação da estrutura resultante do deslocamento (E1).

Adotando esta perspectiva, considero que estamos diante de deslocamentos, pois, em (B) e em (E1), temos enunciados com as marcas linguísticas da enunciação proverbial. Trata-se, ainda, de deslocamentos militantes, que visam a destruir a autoridade do provérbio, estabelecendo uma disputa entre diferentes formações discursivas. Finalmente, por contestar essa autoridade, constituem-se em subversão. Este é o funcionamento discursivo, em (E1), dos novos provérbios.

A noção de funcionamento está presente em Orlandi (1987), quando a autora afirma:

O que importa é destacar o modo de funcionamento da linguagem, sem esquecer que esse funcionamento não é integralmente linguístico, uma vez que delem fazem parte asa condições de produção, que representam o mecanismo de situar os protagonistas e o objeto do discurso. (ORLANDI, 1987, p. 117).

\footnotetext{
${ }^{5}$ Em Maingueneau encontramos o conceito de intertexto: "Por intertexto de uma formação discursiva, entender-se-á o conjunto de fragmentos que ela efetivamente cita" (MAINGUENEAU, 1989, p. 86).
} 
A partir desse conceito, Orlandi vai dizer que "em relação à significação, o laço que liga o discursivo e o linguístico é bastante complexo". (ORLANDI, 1987, p. 118). Para a autora, o linguístico e o discursivo são distintos, mas sua separação é colocada em causa em toda prática discursiva, pois há uma relação entre eles. Nesta medida, a língua aparece como condição de possibilidade do discurso. $O$ processo discursivo está vinculado à exterioridade, isto é, a elementos exteriores à língua. É nesse sentido que, segundo Pêcheux (1988), a língua se apresenta como "a base comum de processos discursivos diferenciados". (PÊCHEUX, 1988, p. 91).

Assim, o exame dos novos provérbios (E1) revela que a alteração do sentido sedimentado, do senso comum, surge a partir de uma ressonância de significação verificada em (EO). O diferente vem pela língua, pela troca de algumas palavras (troca-se "se vai ao longe", por "nunca se chega"; troca-se "quer", por "perde"; trocase "alcança" por "cansa". Parte-se do instituído (devagar se vai ao longe; quem tudo quer, tudo perde; quem espera sempre alcança) e, pela língua e sob diferentes condições de produção, rompe-se esse sentido cristalizado pelo tempo, enunciando o diferente (devagar nunca se chega; quem tudo quer, tudo tem; quem espera sempre cansa).

Esta é a ideia de funcionamento, através da qual texto e discurso se determinam mutuamente, são interdependentes. É por isso que, segundo Orlandi, "é possível procurar no texto o que faz com que ele funcione, e é essa sua qualidade discursiva; paralelamente, é no texto, na sua materialidade específica, que se constitui a discursividade." (ORLANDI,1987, p. 230). São as marcas linguísticas que, para a autora, dizem respeito à organização do discurso, sendo responsáveis pelas diferentes formas de funcionamento dos discursos. Para Orlandi (1988), as marcas são pistas. Elas não são encontradas diretamente, sendo preciso teorizar para atingi-las. Além disso, "a relação entre as marcas e o que elas significam é tão indireta quanto é indireta a relação do texto com as suas condições de produção". (ORLANDI, 1988, p. 54).

É por isso que, de acordo com Orlandi (1988), as marcas não são suficientes para caracterizar um funcionamento discursivo. É preciso ainda remetê-las à propriedade, que "tem a ver com a consideração do discurso como um todo em relação a exterioridade, com a situação." (ORLANDI, 1988, p. 25), ou seja, com as instituições, com o contexto sócio-histórico, com a cultura, com a ideologia. 
É neste sentido que as marcas linguísticas presentes nos novos enunciados (E1) colocam então em confronto os sentidos produzidos em (EO) - a paciência é um valor a ser cultivado, a ambição é um mal, a calma é benéfica - com outros sentidos, possíveis: é preciso correr atrás do que se quer, ser ambicioso é bom, o conformismo leva à frustração. Entre os dois grupos de enunciados - (A) e (B) cria-se, pois, ao mesmo tempo, um efeito de mesmo e de diferente. E é isso que provoca novos efeitos de sentido em (E1), conduzindo ao diferente, à ruptura de significação.

Se, então, mais uma vez, lembrarmos que o discurso é social e historicamente determinado, perceberemos que, se os provérbios, em (EO), estabelecem uma análise da sociedade de forma muito ampla, quase universal, em (E1) os valores sociais são questionados. As estruturas linguísticas são as mesmas, mas os sentidos mudam, pois inserem os sujeitos em formações discursivas distintas.

A ironia, assim, parece ser uma forma de criar uma contradição entre o sentido cristalizado pelos provérbios e um novo sentido, desejado. E essa contradição devese ao fato do uso de um texto já conhecido - o provérbio - e uma forma, já cristalizada pelo tempo, de imputar valores e normas de conduta.

Assim, jogando sobre o mesmo, sobre sentidos instituídos, ou seja, sobre a ressonância, e produz-se o diferente, a dissonância. Não podemos então considerar o espaço discursivo desses enunciados como parafrástico, nem como um discurso autoritário. Instaura-se, com esses novos enunciados, o domínio do polissêmico e do polêmico, ou seja, do diferente.

\section{BUSCANDO UM EFEITO DE FECHAMENTO}

Volto então às minhas questões iniciais, nas quais me propus a pensar sobre língua, relacionando-a a questões ligadas ao ensino. Penso, então, em diferentes formas de ensino de língua tendo como objeto de análise esses enunciados.

Assim, por exemplo, um ensino mais formalista poderia interessar-se por aspectos gramaticais da língua. O professor poderia, por exemplo, tomar o primeiro enunciado do grupo (E0) - Devagar se vai ao longe - e sua repetição em (E1) Devagar nunca se chega - para explicar a noção de indeterminação do sujeito, através do emprego do pronome "se", que funciona como índice de indeterminação. 
O professor poderia também tomar o segundo enunciado do grupo (E0) - Quem tudo quer, tudo perde - e sua repetição em (E1) - Quem tudo quer, tudo tem - para explicar a noção de pronome indefinido substantivo. Finalmente, o professor poderia, ainda, tomar o terceiro enunciado do grupo (E0) - Quem espera sempre alcança - e sua repetição em (E1) - Quem espera sempre cansa - para falar sobre a noção de advérbio, mostrando a ideia de tempo revelada pelo 'sempre'.

Se, no entanto, o professor adotar uma perspectiva mais ampla do que esta, uma que não trate apenas da gramática, mas que vá além dela, chegando ao discurso, e considerar este como lugar social, em que se observa a relação entre língua e ideologia.

Assim, se há diferentes formas de considerar ou conceituar a língua, a adoção de uma concepção $X$ ou $Y$ conduzirá a uma forma $X$ ou $Y$ de ensino. Somente um ensino que vá além do formal poderá dar conta de enunciados como "Devagar nunca se chega / Quem tudo quer, tudo tem / Quem espera, sempre cansa”.

Nesta perspectiva, a adoção de uma concepção discursiva deve evitar reduzir o discurso à análise da língua ou dissolvê-la no trabalho histórico sobre a ideologia como representação.

O importante, portanto, na minha perspectiva, é o professor de língua ter consciência de questões como essas, é o professor questionar as 'verdades' aprendidas, as crenças tão estabilizadas sobre língua, gramática, leitura, interpretação.

Quando se trata de ensino, é fundamental o profissional ter conhecimento das diferenças e dos limites entre perspectivas teóricas distintas. Mas também é preciso que, acima de disputas teóricas, muitas vezes movidas à vaidade ou ao desejo de demarcar território, todos nós tenhamos consciência de nossa tarefa: que ensinar língua é ensinar a ler, ensinar a interpretar. Pensar sobre questões de ensino significa, então, levar muito a sério a relação língua - leitura - interpretação discurso.

Por isso, através do pequeno gesto de análise aqui realizado, tentei mostrar não uma fórmula de ensino, mas uma concepção diferente: a discursiva. Tentei refletir sobre a importância de reconhecer, em um enunciado ou em um texto, marcas linguísticas (pistas) que revelam que tanto autor quanto leitor assumem uma posição de sujeito historicamente determinada. 
Espero ter demonstrado que o sujeito, ao usar a língua, em sua materialidade, e ideologicamente determinado, produz sentidos que se cruzam com os sentidos de sujeitos também ideologicamente determinados e sob efeito da memória discursiva. É assim que se desenrola o processo discursivo da leitura e os diferentes gestos de interpretação. E é assim que a língua pode ser pensada, para muito além do que nos permitiria um estudo tradicional.

Escapar desse caráter autoritário significa, para professores e alunos, expor-se à multiplicidade dos sentidos, a sentidos possíveis, concordando ou discordando deles, na dinâmica da interlocução. Significa construir um espaço para o outro, aluno (ouvinte), e construir a possibilidade de ele mesmo, professor(locutor), colocar-se como ouvinte.

Uma forma diferente de pensar a língua pode permitir a recuperação de sentidos encobertos pela fixidez do discurso parafrástico e possibilitar que se entenda que mesmo a mais simples repetição sempre significa diferentemente, pois introduz uma modificação no processo discursivo. Uma forma que fuja do meramente gramatical poderá possibilitar a percepção das diferenças linguísticas, mas deverá também evidenciar a diferença de sentido produzida pela diversidade das construções.

Uma forma diferente de pensar a língua permitirá perceber, finalmente, que onde há linguagem, há confronto de sentidos, já que a significação não é imóvel, e que, portanto, dizer não é informar, ensinar não é inculcar. Em suma: ensinar é produzir sentidos.

\section{REFERÊNCIAS}

ALTHUSSER, L. Aparelhos Ideológicos de Estado. Rio de Janeiro: Graal, 1992.

COURTINE, J. J.; MARANDIN, J. M. Quel objet pour l'analyse du discours? In:

Matérialités discursives. Colloque à l'Université Paris X-Nanterre (1980). Lille: Presses Universitaires de Lille, 1981. [s.p.]

GERALDI, J. W. Portos de Passagem. São Paulo: Martins Fontes, 1993.

GRESILLON, A.; MAINGUENEAU, D. Polyphonie, proverbe et détournement. Langages, n. 73, [s. I.], p. 112-125, 1984.

INDURSKY, F. A fala dos quartéis e as outras vozes: uma análise do discurso presidencial da terceira república brasileira. Campinas: Editora da UNICAMP, 1997. 
LAGAZZI, S. O desafio de dizer não. Campinas: Pontes, 1988.

MAINGUENEAU, D. Novas Tendências em Análise do Discurso. Campinas; Pontes: Editora da UNICAMP, 1989.

ORLANDI, E. A linguagem e seu funcionamento - as formas do discurso. 5. ed. Campinas: Pontes, 1987.

ORLANDI, E. Análise do Discurso: princípios e procedimentos. Campinas: Pontes, 1999.

ORLANDI, E. Destruição e construção do sentido: um estudo da ironia. Série Estudos, Faculdades Integradas de Uberaba, [s. I.], n. 12, 1986.

PÊCHEUX, M. Análise Automática do Discurso: três épocas. In: GADET, F.; HAK, T. (org.). Por uma análise automática do discurso. Campinas: Ed. Unicamp. 1990. p. 311-318. Originalmente publicado em 1983.

PÊCHEUX, M. Semântica e Discurso: uma crítica à afirmação do óbvio. Campinas: Ed. Unicamp, 1988.

PÊCHEUX, M.; FUCHS, C. A propósito da Análise Automática do Discurso. In: GADET, F.; HAK, T. (org.). Por uma análise automática do discurso. Campinas: Ed. Unicamp, 1990. p.159-249. Originalmente publicado em 1975.

PEREIRA, A. E. Na inconsistência do humor, o contraditório da vida: o discurso proverbial e o discurso de alterações. 1994. Tese (Doutorado em Letras - Linguística Aplicada) - Curso de Pós-Graduação em Letras do Instituto de Letras e Artes, Pontifícia Universidade Católica do Rio Grande do Sul, Porto Alegre, 1994.

\section{Sobre a autora}

\section{Marilei Resmini Grantham}

Possui Doutorado em Letras pela UFRGS (2002), Mestrado em Letras pela Universidade Federal do Rio Grande do Sul - UFRGS (1996) e Graduação em Letras pela Universidade Federal do Rio Grande - FURG (1979). Atualmente é aposentada pela Universidade Federal do Rio Grande FURG - onde trabalhou no período entre 1989 e 2006, atuando como Professora de Língua Portuguesa, Prática de Ensino e Metodologia do Ensino. Atuou ainda no Curso de Especialização Lato Sensu, ministrando a disciplina de Teorias do Texto e do Discurso, com enfoque na Análise do Discurso. 